\title{
Motivaciones de la expresión metafórica venezolana El papá de los helados*
}

\author{
MAIKEL RAMÍREZ ÁLVAREZ** \\ maramirez@usb.ve
}

ANA MARÍA RAMÍREZ DÍAZ *** anaramirez@usb.ve

Forma de citar este artículo: Ramírez Álvarez, M., \& Ramírez Díaz, A.M. (2016). Motivaciones de la expresión metafórica venezolana El papá de los helados. Cuadernos de Lingüística Hispánica, (28), 127-145. doi: http://dx.doi.org/10.19053/0121053X.4912

* Artículo de investigación científica.

** Magister en Literatura Latinoamericana, UPEL - Maracay; profesor en la especialidad de Inglés en la Universidad Pedagógica Experimental Libertador, Instituto Pedagógico "Rafael Alberto Escobar Lara"; profesor en la categoría de agregado del área de Inglés en la Universidad Simón Bolívar Sede del Litoral, Edo. Vargas, Venezuela; investigador en temas de análisis del discurso, pragmática, lingüística cognitiva, cine y literatura latinoamericana.

*** Magister en Lingüística, UPEL - Maracay; profesora en la especialidad de Lengua y Literatura en la Universidad Experimental Libertador, Instituto Pedagógico "Rafael Alberto Escobar Lara"; profesora en la categoría de asistente en el área de Lenguaje de la Universidad Simón Bolívar Sede del Litoral, Edo. Vargas, Venezuela; investigadora en temas de análisis del discurso, pragmática, metáforas, representaciones, género e identidades. 


\title{
Resumen
}

El objetivo de esta investigación fue explicar las motivaciones de la expresión metafórica del habla cotidiana venezolana "el papá de los helados". Teóricamente, se sustenta en Cuenca y Hilferty (1999), Johnson (2006), Díaz (2006), Lakoff y Johnson (2009) y Kövecses (2010). En cuanto a la metodología, es una investigación descriptiva e interpretativa. Los resultados son los siguientes: (a) la imagen esquemática de la metáfora conceptual EL PODER ES ARRIBA se proyecta sobre la imagen esquemática de un helado en virtud de su verticalidad y acumulación hacia arriba; (b) se recurre al helado, además, dado que lo dulce metaforiza a lo sublime; (c) el dominio del padre se emplea, debido a que es el miembro que encabeza una familia, la autoridad simbólica; (d) la imagen esquemática de el papá de los helados, a saber, el helado más grande de todos se proyecta sobre un hombre que destaque en determinado aspecto. En conclusión, la expresión metafórica "el papá de los helados" es motivada por un conjunto complejo de metáforas primarias, imágenes esquemáticas y metáforas cotidianas que surgen de las experiencias concretas y corrientes de los individuos, para designar a un hombre con poder sobre otros en algún aspecto de la vida diaria.

Palabras clave: Metáfora conceptual, motivación, imagen esquemática.

\section{Exploring the Venezuelan Metaphorical Expression: "El papá de los helados"}

\begin{abstract}
The main objective of this paper is to explain the causes behind a metaphorical expression of Venezuelan daily speech: "el papá de los helados" [the father of ice cream]. This research is theoretically supported by the work of Cuenca and Hilferty (1999), Johnson (2006), Díaz (2006), Lakoff and Johnson (2009) and Kövecses (2010). Regarding the methodological design, this is a desk-based, descriptive, interpretative study. The results are the following: (a) the system image of the conceptual metaphor "EL PODER ES ARRIBA" [the power is up] is projected over the system image of "helado" [ice cream] because of its verticality and upwards accumulation. (b) The image of ice cream is used
\end{abstract}


here because sweetness is a metaphor for the sublime. (c) The dominance of the father figure is employed because he is the head of the household, a symbolic authority. (d) In the system image: "el papá de los helados", the biggest ice cream is projected over a man who stands out in a particular aspect. To conclude, the metaphorical expression "el papá de los helados" is motivated by a complex combination of primary metaphors, system images and everyday metaphors that emerge from the concrete experiences of the individuals, in order to name a man with power upon the others in a given aspect of daily life.

Key words: Conceptual metaphor, motivation, system image

\section{Motivations de l'expression métaphorique vénézuélienne Le papa des glaces (El papá de los helados)}

\section{Résumé}

L'objectif de cette recherche a été celui d'expliquer les motivations de l'expression métaphorique du parler quotidien vénézuélien "le papa des glaces". En théorie, cela trouve son soutien chez Cuenca et Hilferty (1999), Johnson (2006), Díaz (2006), Lakoffet Johnson (2009) et Kövecses (2010). Quant à la méthodologie, il s'agit d'une recherche descriptive et interprétative. Les résultats sont: (a) l'image schématique de la métaphore conceptuelle LE POUVOIR SE SITUE AU DESSUS se projette sur l'image schématique d'une glace en vertu de sa verticalité et accumulation vers le haut; (b) on fait recours à la glace, en plus, parce que le doux métaphorise le sublime; (c) la domination du père s'emploie, dû au fait qu'il est la tête d'une famille, l'autorité symbolique; (d) l'image schématique du papa des glaces, à savoir, la glace la plus grande de toutes, se projette sur un homme qui se fait remarquer dans un aspect déterminé. En conclusion, l'expression métaphorique "le papa des glaces" est motivée par un ensemble complexe de métaphores primaires, d'images schématiques et de métaphores quotidiennes qui surgissent des expressions concrètes et courantes des individus, pour désigner un homme avec du pouvoir sur autrui dans un aspect de la vie quotidienne.

Mots clés: Métaphore conceptuelle, motivation, image schématique. 


\section{Motivações da expressão metafórica venezuelana \\ El papá de los helados (0 pai dos sorvetes)}

\section{Resumo}

O objetivo desta pesquisa foi explicar as motivações da expressão metafórica da fala cotidiana venezuelana "el papá de los helados". Teoricamente, se sustenta em Cuenca e Hilferty (1999), Johnson (2006), Díaz (2006), Lakoff e Johnson (2009) e Kövecses (2010). Enquanto à metodologia, é uma pesquisa documental, descritiva e interpretativa. Os resultados são os seguintes: (a) a imagem esquemática da metáfora conceptual 0 PODER É PARA CIMA se projeta sobre a imagem esquemática de um sorvete em virtude de sua verticalidade e acumulação para cima; (b) se recorre ao sorvete, além disso, dado que o doce metaforiza o sublime; (c) o domínio do pai se emprega, devido a que é o membro que encabeça uma família, a autoridade simbólica; (d) a imagem esquemática de el papá de los helados, a saber, o sorvete maior de todos se projeta sobre um homem que se destaca em um determinado aspecto. Em conclusão, a expressão metafórica "el papá de los helados" é motivada por um conjunto complexo de metáforas primárias, imagens esquemáticas e metáforas cotidianas que surgem das experiências concretas e diárias dos indivíduos, para designar a um homem com poder sobre outros em algum aspecto da vida diária.

Palavras chave: Metáfora conceitual, motivação, imagem esquemática. 


\section{Introducción}

Parte de la producción lingüística de los hablantes de una lengua se destina a asignarles un nombre a los demás miembros de la comunidad. En el filme mexicano El infierno, del cineasta Luis Estrada, por poner un ejemplo, se refieren al capo de la droga más importante de la región como 'el mero mero', mexicanismo que, según Oxford Dictionaries, alude a la persona más importante en una situación. Si extrapolamos esta idea al español de Venezuela hablado por jóvenes, podría emplearse 'el chivo', como lo registra Pérez (2002), o, si esto se constriñera al habla coloquial de los caraqueños, se diría que el jefe o persona de poder es 'el chivo que más mea', como D' Alessandro Bello (2009) lo asienta en su diccionario de coloquialismos empleados por los hablantes de la capital venezolana.

Las expresiones venezolanas apuntadas arriba, ya se habrá notado, comparten la condición de referirse a la persona poderosa en términos de un elemento ostensiblemente distinto, a saber, un chivo. Similarmente, la investigación que sigue se preocupó por una expresión empleada para hablar de un hombre poderoso, pero cuyo significado no puede tomarse de manera literal: el papá de los helados, expresión que representa como un helado gigantesco a un hombre que tiene poder en algún aspecto de la vida, sea esta superioridad manifestada en los deportes, la música, los estudios, o cualesquiera dominios de la cotidianidad.

En concreto, siendo la arbitrariedad del signo linguístico, esto es, la relación del significante (aspecto fonético) con su significado (aspecto semántico), uno de los pilares en los que se ha fundamentado la linguística, este estudio propone orientarse a contravía al tratar de dar respuesta al cómo la expresión metafórica antedicha se encuentra intricadamente relacionada con factores experienciales y culturales que la motivan. En una palabra, allí donde Saussure (1945) señala que cualquier secuencia de sonidos podría representar la idea de 'sur' (p. 130) (es decir, la misma idea podría representarse con las secuencias de 'camión', 'zapato' o 'dinosaurio'), se constatará que se es el papá de los belados y no el papá del pabellón, el sobrino del café con leche o el tío de los helados, por motivos cuya naturaleza se precisarán en esta investigación. A razón de esto y según lo descrito con anterioridad, el objetivo del presente estudio se enfocó en explicar las motivaciones de la expresión metafórica del español de Venezuela el papá de los helados. Dicha expresión se constituye con dos dominios, uno fuente: el papá de los helados; 
y otro meta: el hombre destacado en un campo. Pero, en el tránsito de ese mapeo de conceptos otras nociones se superponen, y en ese hecho se centra nuestra atención en la investigación que presentamos. A continuación, veamos la siguiente figura para visualizar los componentes de la expresión metafórica en cuestión:

Figura 1. Proceso de metaforización de la expresión metafórica el papá de los helados

\begin{tabular}{|ccc|}
\hline DOMINIO FUENTE & & DOMINIO META \\
\cline { 2 - 3 } & & \\
EL PAPÁ DE LOS HELADOS & PODER & HOMBRE DESTACADO EN UN \\
(EL HELADO MÁS GRANDE DE & Paterno & CAMPO \\
TODOS) & Arriba & \\
& Prestigio & \\
\hline
\end{tabular}

En atención al objetivo trazado arriba, esta investigación se apoya en: (a) Lakoff y Johnson (2009), para desarrollar la noción de metáfora conceptual, aspecto de primer orden en este estudio, y Lakoff (2004), en lo tocante a este tipo de metáforas cuando se aplica a la conceptualización de países; (b) Cuenca y Hilferty (1999), a fin de ser orientada a través del concepto de metáfora de imagen; (c) Díaz (2006), por cuanto ha estudiado las motivaciones y características de la metáfora conceptual de tipo orientacional El PODER ES ARRIBA; (d) Kövecses (2010) y Johnson (1987, 2007), que permitirán establecer la motivación de la expresión el papá de los helados en términos de metáforas básicas, el contacto corporal del individuo con el mundo que habita y la impronta de la cultura en la mente y, por tanto, en la lengua de los hablantes; y (e) Lakoff (1987) para resolver las categorías mentales de los hablantes del español de Venezuela en términos de prototipicidad.

Ante el tradicional acercamiento al estudio de la metáfora, que designaba a esta como un recurso del cual literatos y retóricos podían echar mano para embellecer y hacer efectivo el mensaje, Lakoff y Johnson (2009) evidenciaron en una investigación seminal que no solo los hablantes se expresan con metáforas, sino que, en sustancia, su sistema conceptual es de naturaleza metafórica. Para explicarlo en otros términos, los hablantes conceptualizan conocimientos incipientes y abstracciones (dominio metas) por medio de conocimientos previos y, por lo común, objetos concretos (dominio fuente). Ilústrese esta formulación con el caso de la metáfora conceptual EL AMOR ES UNA GUERRA, en la que los enemigos corresponden con los amantes, la conquista con lograr el amor, rendirse con enamorarse finalmente, y que se manifiesta concreta y lingüísticamente con expresiones como: 'la conquisté', 'su amor me venció' y 'lucharé por tu amor'. En estos ejemplos, como se ve, se transparentan tanto un dominio fuente (la guerra) como un dominio meta (el amor), en el que este último, cuya existencia es intangible y mental, se conceptualiza a través de la condición concreta del primero. 
Afirma Lakoff (2004), por otro lado, que nuestro sistema conceptual representa, de manera expansiva y vivaz, una nación como una persona. Esta metáfora funciona como un principio rector de las relaciones internacionales entre Estados. Esta conceptualización, asimismo, comporta la idea de que hay naciones adultas y naciones infantes, lo cual implica que las naciones han alcanzado una madurez (metafórica) que corresponde con la industrialización. A manera de ejemplo, fijémonos en el titular de prensa "La industria de videojuegos en Venezuela está en pañales”, en el que se razona sobre la incipiente industria de videojuegos en Venezuela, como si de un pequeño infante se tratase.

Continuando con estos presupuestos teóricos, Cuenca y Hilferty (1999) hacen notar que una metáfora de imagen, en cambio, no proyecta un concepto sobre otro, como ocurre en el ejemplo de arriba, sino que, ante todo, inequívocamente, proyecta una estructura 0 imagen esquemática desde el dominio origen al dominio meta. Para precisar esta tipología, veamos que la palabra 'koala', referida al bolso diminuto que una persona se cuelga de la cintura, tiene su génesis en este tipo de metáfora. La proyección que se lleva a cabo acá es la de la imagen esquemática del conocido marsupial australiano, que, si prestamos atención a las acepciones que registra el Diccionario de la Lengua Española (2015) sobre otro marsupial australiano, el canguro, entendemos que se sustenta en la capacidad de poder llevar una carga dentro de la bolsa que tiene en la parte delantera de su cuerpo, como también la tiene este último animal.

Díaz (2006), por su parte, se ha encargado de estudiar con hondura la metáfora conceptual EL PODER ES ARRIBA, y su trabajo ha arrojado una profusión de variantes de esta metáfora, que asignan las funciones de dominador y dominado en diversas situaciones de la sociedad. Como es previsible, si el poder es arriba, por implicación, el dominado se encuentra abajo. Sugiere Díaz que el origen de esta metáfora se relaciona con 'humillar', que etimológicamente significa 'humilde', y esta a su vez entronca con 'humus', que significa 'tierra'. Entre los ejemplos paradigmáticos de este tipo de metáfora conceptual en boca de los hablantes del español, podemos mencionar: 'el equipo de fútbol local aplastó al visitante', 'ese ricachón ve a los demás por debajo del hombro' y 'el pueblo se encuentra bajo el yugo del tirano'. De conformidad con la línea argumental que tratamos, se aprecia que las expresiones metafóricas enumeradas se rigen por la idea de que quien ejerce un poder se encuentra en una posición espacial más elevada que la persona subordinada.

Ahora, no obstante, la aproximación al estudio del lenguaje ha mantenido por casi un siglo que uno de los rasgos esenciales de este es su arbitrariedad. Saussure (1945), como es sabido, sostiene que la relación entre el significante (la secuencia de sonidos o parte material) y el significado (la idea o parte inmaterial) del signo lingüístico es arbitraria. Por consiguiente, la idea de 'carro' podría haber sido expresada indistintamente 
por las secuencias de sonidos de las palabras 'mar', 'zanahoria' o 'jabalí', como, en efecto, lo probaría el hecho de que la idea de 'carro' es expresada en español con una secuencia de sonidos muy diferentes a las del inglés y el francés, con las palabras 'car' y 'voiture', respectivamente. Sin embargo, al analizar una metáfora, sobre todo contrastivamente, es posible detectar que no hay arbitrariedad sino motivación. Nótese, por ejemplo, las metaforizaciones del hombre homosexual, estudiadas por Ramírez y Ramírez (2013), con palabras como 'hueco', en Guatemala; 'argolla', en Venezuela; y 'rosquete', en Perú, que pese a tener diferentes secuencias de sonidos manifiestan la misma motivación: el hombre homosexual tiene actividad por medio de su ano. Este elemento metonímico, de resultas, pasa a representar a un hombre homosexual.

Sin embargo, esta investigación, siguiendo los postulados teóricos de Lakoff y Johnson (2009), se guía por medio de la noción de motivación de la metáfora conceptual que hemos anticipado. En otras palabras, una metáfora conceptual, como se demostró arriba, tiene base en la experiencia corporal y cultural del individuo. Desde esta óptica, una persona que escarba dentro de una olla para extraer lo último que queda de un alimento podrá tomar esta vivencia y convertirla en material linguístico en años posteriores, cuyo significado metafórico en un contexto político es el de un acto de desfalco total, como por ejemplo: "el exgobernador raspó la olla antes de fugarse al extranjero".

En este orden de ideas, Köveceses (2010) muestra un cuadro amplio de las motivaciones que pueden encontrarse detrás del uso de metáforas conceptuales. Una de ellas son las metáforas primarias que dan origen a otro tipo de metáforas conceptuales más complejas. Retomando el ejemplo de EL AMOR ES UNA GUERRA, anotado arriba, leamos la siguiente representación de la relación sexual elaborada por la escritora argentina Pola Oloixarac (2008):

De pie, como una sombra proyectándose sobre su víctima, collazo me examina en silencio. Las luces dicroicas del techo estallan sobre su calva, como francotiradores entrenados; su bigote se ensancha a los lados, y sonríe. Da por sentado que la batalla lo favorece y examina casi obscenamente su dominio teórico sobre el terreno a disputar (p. 121).

Dejando la construcción literaria a un lado (francotiradores), se puede observar que este extracto se apoya en la metáfora conceptual EL AMOR ES UNA GUERRA. Con todo, es fácil darse cuenta que esta es una explicación parcial del extracto literario, puesto que reconocemos que la metáfora del amor como guerra se corresponde con los sentimientos entre los amantes. De donde se deduce que estas proyecciones metafóricas se extienden hasta las relaciones sexuales que los amantes mantienen. De hecho, la expresión 'hacer el amor' ya sugiere que tiene propiedades metafóricas como las que hemos revisado, pues 
'amor' es una abstracción. Este es un caso ejemplar de una metáfora conceptual que se deriva de otra, que opera solo si otra la precede 0 , por así decirlo, la sostiene como un sustrato base.

Otra modalidad de motivación toma lugar cuando dos eventos se correlacionan. Un ejemplo oportuno con el que Kövecses (2010) nos ilumina es el del calor que siente una persona cuando se enfurece, ya que, es sabido, la temperatura corporal aumenta debido a la aceleración de la sangre que bombea el corazón ante el estímulo. Por esa razón, existen expresiones metafóricas que representan a la rabia como un calor que la persona padece, en las que el dominio fuente es concreto (el calor) y el dominio meta abstracto (la rabia), como se aprecia en los siguientes casos: "me hierve la sangre cuando me hacen esperar", "echaba candela después de que el jefe lo insultó delante de todos" y "el ambiente se calentó tras la paliza que el Barcelona le propinó al Real Madrid".

Johnson (1987, 2007), por su parte, mantiene que el significado que los individuos tienen de las cosas se origina de la conjugación de su aparato sensorio-motor con las emociones en interacción con el mundo. Este conglomerado de la experiencia del individuo, de acuerdo con Johnson, es proyectado en casos que a través de la imaginación sean percibidos como similares. Nótese enfáticamente el componente emocional al que este investigador hace referencia. Otro aspecto que es conveniente resaltar del aparataje teórico de Johnson es que el significado se forma en una etapa preconceptual y prelenguaje. Para explicarlo con un ejemplo, pensemos en un niño que observa a diario cómo un vaso se llena de agua. Esta situación determinará dos dominios: (a) más y (b) arriba, lo que se concretiza metafóricamente como MÁS ES ARRIBA, reconocible en una expresión como: "el precio del pollo está por las nubes" (mayor precio es subir). Como quiera que sea, el significado acá surge de la experiencia directa aun cuando para el niño no exista el concepto de cantidad ni de elevación, como tampoco haya desarrollado el lenguaje.

Para finalizar este apartado teórico, se precisa asimilar la noción de prototipo formulada por Lakoff (1987), según la cual los seres humanos pensamos las categorías en términos de miembros con grados prototípicos que surgen de la interacción de la experiencia y la imaginación con el entorno físico. Referencial de esta formulación puede ser un pingüino, ave que, para pobladores del llano venezolano, o de otras regiones del mundo, salvo el gélido hemisferio sur, podría ser no-prototípico, en razón de que no vuela, condición que resulta un factor de prototipicidad dentro del contexto natural del llano venezolano, que suele estar cruzado en el firmamento por loros, gavilanes, zamuros y otros ejemplares voladores. De lo que se deduce que el pingüino no sea una imagen que se presente en la mente del hablante del llano al hablar de la categoría, lo que, desde luego, tiene consecuencia en las acciones que lleve a cabo en relación con esta clase de ave. 


\section{Metodología}

Desde el punto de vista metodológico, el estudio fue abordado a partir de la óptica del enfoque cualitativo, ya que permitió describir el fenómeno con el fin de intentar comprenderlo y analizarlo a la luz de diversas teorías, en este caso linguísticas, que dieron respuesta al tema discursivo y/o cognitivo. Cabe destacar que, este enfoque se complementó con los aportes de la linguística cognitiva, ya que es la rama de la lingüística que le da un lugar privilegiado a la cognición, lo que incluye metáforas conceptuales, categorías, el significado con base corporal y la función de las emociones en la cognición humana. Esta rama de la lingüística permitirá develar las motivaciones que se llevan a cabo en la expresión metafórica del español de Venezuela el papá de los helados.

Por lo que respecta al corpus seleccionado, este se constituyó con diez (10) titulares de prensa que serán los ejemplos ilustrativos para disertar sobre las motivaciones, pues, como se verá, la expresión y su contexto no varían mucho. Es por ello que, se debe destacar que tan solo contamos con esta cantidad, debido a que, en primer lugar, y como criterio de selección, se consideraron aquellos titulares que cumplieran con la característica de estar construidos con la expresión el papá de los helados, debido a que tal expresión conformaría, además, nuestra unidad de análisis; en segundo lugar, consideramos que el corpus no requería ser tan extenso para efecto de explicar las motivaciones de dicha expresión, puesto que en todas se reiteran las mismas motivaciones. En lo sucesivo, presentamos el corpus seleccionado:

Tabla 1. Corpus de la investigación

\begin{tabular}{|c|c|}
\hline $\begin{array}{l}\text { 1. Psy es el papá de los helados en la Enciclopedia } \\
\text { británica" (El Propio: 01/06/2013) }\end{array}$ & $\begin{array}{l}\text { 2. "Europa quiere ser el papá de los helados de las } \\
\text { redes 5G" (Lea noticias: 12/02/2014) }\end{array}$ \\
\hline $\begin{array}{l}\text { 3. "Manuel Da Silva: el papá de los helados" } \\
\text { (Primicia: 07/11/2014) }\end{array}$ & $\begin{array}{l}\text { 4. "Vilanova cree que Pep es el papá de los } \\
\text { helados" (El Propio: 01/16/2013) }\end{array}$ \\
\hline $\begin{array}{l}\text { 5. "Noel Sanvicente tiene apoyo del papá de los } \\
\text { helados para dirigir la vinotinto" (Noticias } \\
\text { Venezuela: } 18 / 02 / 2014)\end{array}$ & $\begin{array}{l}\text { 6. "Messi es el papá de los helados según } \\
\text { Beckham" (El Propio 11/04/2013) }\end{array}$ \\
\hline $\begin{array}{l}\text { 7. "El papá de los helados: Luís Arquímedes sigue } \\
\text { arrasando!" (Noticias Venezuela: } 28 / 08 / 2015)\end{array}$ & $\begin{array}{l}\text { 8. "Cabrera es el papá de los helados en la MLB" } \\
\text { (El guía: 07/05/2013) }\end{array}$ \\
\hline $\begin{array}{l}\text { 9. "Messi sigue siendo el papá de los helados para } \\
\text { la prensa" (El propio: } 13 / 10 / 12)\end{array}$ & $\begin{array}{l}\text { 10."Gilberto Santa Rosa es el papá de los helados } \\
\text { en la Salsa" (El "polifacético" cantante José } \\
\text { Giovanni: 02/02/13) }\end{array}$ \\
\hline
\end{tabular}




\section{Resultados}

Seidentificó que, en un primer momento, parte del sustrato de la expresión metafórica venezolana el papá de los helados se apoya en la metáfora orientacional primaria EL PODER ES ARRIBA, contenida en expresiones del habla cotidiana, para ilustrar, veámoslo en dos casos paradigmáticos: “iqué grande es Lionel Messi!”, en el que metaforizar a Messi como alguien de mayor altura corporal que el resto de los jugadores significa ser mejor jugador que ellos, o "Es un jefe joven porque supo escalar rápidamente", en la que el acto físico de escalar metaforiza los logros que una persona ha alcanzado en términos profesionales, lo que, a la postre, se manifiesta en poder dentro del ámbito laboral.

Partiendo de las coordenadas señaladas arriba, nótese que la orientación espacial sugerida en la metáfora conceptual EL PODER ES ARRIBA se proyecta sobre la imagen esquemática de un helado en virtud de que este tipo de golosina ocupa una posición vertical en la topografía en la que se encuentran los hablantes y, estrictamente, en el recorrido que se inicia, por lo general, a la altura del abdomen y culmina en la boca de los consumidores. Complementario a esta orientación vertical, cuando se consume el helado es el hecho de que aun este aumenta su tamaño en la medida que acumula más crema o capas de caramelo hacia arriba, aspecto que resulta clave, como se demostrará en el siguiente apartado. Por lo pronto, acordemos que es la verticalidad del helado lo que autoriza el mapeo de la metáfora conceptual EL PODER ES ARRIBA. Ni qué decir que esta motivación deroga dominios como el perro caliente, la hamburguesa, la pizza, la cachapa, entre tantos otros, en razón de que todos estos alimentos, en contraste con el helado, se orientan de manera horizontal y su aumento depende de una extensión en el mismo sentido espacial, como, pongamos por caso, pizzas pequeñas, medianas y grandes, todas prolongadas en términos horizontales.

En cualquier caso, y a manera de ejemplos adicionales, consideremos un grupo de expresiones metafóricas del habla cotidiana venezolana que, aun cuando cristalicen evaluaciones sociales negativas, se sostienen con el mismo esquema de la expresión $e l$ papá de los helados. Pensemos, por ejemplo, en 'creerse la tapa del frasco' y 'venirse a pique'. La primera, empleada para acusar a alguien de creerse con más poder que los demás, en la que, por descontado, la persona es una tapa metafórica (está arriba); en la segunda, alguien que pierde poder es representado como un avión que se precipita a tierra. Igualmente, un análisis contrastivo nos permite poner nuestra expresión metafórica de estudio al lado de la anglófona de variante australiana The tall poppy, en la que una flor más alta que las otras indica el poder que ejerce sobre ellas. 
A estas alturas, se habrá reparado en la presencia de otros alimentos en nuestro entorno que pueden consumirse con una orientación vertical, como es el caso de un cambur, por mencionar apenas un ejemplo. Por lo que atañe a casos similares, conviene reiterar, por un lado, la idea de acumulación vertical que es una de las correspondencias que los hablantes resaltan entre EL PODER ES ARRIBA y el papá de los helados; por otro lado, alimentos como el cambur carecen de partes delimitadas con claridad. En una palabra, aun cuando los digerimos en posición vertical, no podemos indicar con certeza cuál es su parte superior y cuál es su parte inferior.

Ahora bien, un posible contraargumento a la explicación anterior es que, en efecto, existen otros alimentos tanto con una orientación vertical como con delimitación que nos permitirían identificar sus bordes superiores e inferiores. Ejemplos ilustrativos de estas excepciones son las bebidas gaseosas, los batidos y los jugos naturales, entre otros más. Apresurémonos a señalar que otra de las motivaciones de la expresión el papá de los belados estriba en que un helado, de acuerdo con nuestra experiencia corporal y el conocimiento de cómo opera la cultura, es un alimento dentro de la categoría social 'delicatesen'. Sabemos, por lo demás, que un postre no solo es un plato refinado per se, sino que constituye una comida habitual que demuestra abolengo en la mesa de aristócratas y la clase alta, que pueden disfrutar de ese lujo, entre tanto, veremos que las familias pobres se deben contentar con alimentarse con lo estrictamente necesario para subsistir.

Conviene prever un justo contraargumento que acusaría lo no imprescindible de los alimentos mencionados arriba en la mesa de personas de un estrato social menos pudiente. Ante esto, cabe responder que esta investigación se orientó por los preceptos teóricos de la linguística cognitiva, lo que, sin duda, implica estudiar los fenómenos de la lengua en términos de prototipicidad. Para decirlo todo, allí donde el sistema de categorías decimonónico habla de miembros con propiedades necesarias y suficientes, la lingüística cognitiva, en la figura de Lakoff (1987), habla de miembros prototípicos que pueden variar en cada cultura y en distintas épocas. ¿Qué implicaciones tiene esto en la investigación que se presenta acá? Específicamente, dictamina que en la mente de un hablante hay miembros prototípicos y otros no prototípicos que se van alejando hasta pasar a otra categoría. De manera que, aunque un helado no sea imprescindible en la mesa de un hablante del español de Venezuela menos pudiente igual representará un alimento delicatessen, pues esta noción circula en la cultura en la que es, está y hace, de la misma forma que un millonario no necesita haber vivido en una barriada para tener una idea clara de qué va a encontrar allí.

En cualquier caso, Onfray (2015) ha revisado lo que diversos alimentos y platos han significado para los filósofos desde la antigua Grecia hasta el siglo xx. Entre sus hallazgos 
podemos encontrar los postres como uno de los platos asociados a la vida burguesa, y por lo que respecta al artista futurista Marinetti, el helado, entre otros alimentos, se convierte en una de las formas placenteras de hacer arte y de emplear todo un aparato tecnológico como revolución social.

En este sentido, el helado como repositorio de la metáfora de poder no solo depende de su verticalidad, sino, además, de su condición prototípica de alimento refinado y lujoso, características que no tienen, o al menos conservan en un grado sumo inferior o no prototípico, las bebidas gaseosas, los batidos y los jugos naturales, o cualquier otro alimento con rasgos similares a estos. Hemos de hacer notar, valiéndonos nuevamente del análisis contrastivo, que la lengua española, la inglesa y la francesa disponen de otras expresiones metafóricas que parten de la crema, como metonimia para representar personas con poder: (b1) la crema y nata; (b2) la crema de la crema; (c) the cream on the crop; y (d) créme de la créme. (b2) conforma un caso de importancia para la argumentación que trazamos acá, ya que combina tanto una verticalidad intensa (una crema encima de otra) como lo refinado del alimento, asunto este que hemos tratado a lo largo de este apartado.

En el siguiente movimiento del proceso, el dominio del padre proyecta su tamaño y su autoridad sobre un helado. El padre, según nuestra tradición familiar, y como lo han constatado diversos campos de estudios, entre ellos el psicoanálisis en sus vertientes freudianas y lacanianas, representa la primera autoridad que los individuos conocen antes de entrar en la sociedad, en la que conocerán las leyes, la constitución y otras reglas de su funcionamiento. Como se sabe, esto ocurre cuando el individuo atraviesa sus primeros años de vida, aquellos en los que ni siquiera hay una identidad sexual, sino que, por lo contrario, la figura paterna viene a ser el elemento que define la identidad y el deseo del individuo. La motivación que acá toma lugar, por consiguiente, reposa en la experiencia corporal y cultural que tenemos de un padre de familia. Pongámoslo en estos términos concretos: si nos portamos mal, nuestro papá nos increpa; si nos sentamos a comer en la mesa, nuestro padre encabeza la ceremonia; si se debe hacer alguna labor demandante de fuerza física, nuestro padre resolverá el problema.

En conformidad con lo anotado arriba, resulta propicio revisar productos culturales que han usado la metáfora del padre como representación de poder, que incluye novelas como Pedro Páramo, de Juan Rulfo, en la que la imagen del padre biológico se solapa con la del caudillo que controla el pueblo a su antojo; y el cántico entonado por los argentinos los días posteriores al 8 de julio de 2014, tras la goleada 7-1 que la selección de fútbol alemana le propinó a Brasil durante las semifinales del Mundial de fútbol Brasil 2014. Sabido es que Argentina y Brasil han mantenido una rivalidad futbolística por años. 
De allí que los argentinos cantaran: "Brasil decime qué se siente tener en casa a tu papá", con el que se autorrepresentaban como padres de los brasileños.

Por último, se constata que el dominio fuente el papá de los helados se proyecta sobre un hombre que descuelle en cualquier disciplina del quehacer cotidiano, lo cual arroja la fórmula $A$ es $B$. Si tomamos como referencia el titular de prensa: "Messi es el papá de los helados según Beckham", se observa que para que el jugador argentino de fútbol sea representado metafóricamente como un helado más grande que el resto de un conjunto, lo que lo representa como el mejor jugador de todos, se llevaron a cabo las motivaciones mencionadas en los párrafos que anteceden. De igual manera, el titular "Psy es el papá de los helados en la Enciclopedia Británica", como ya se ha visto anteriormente, evidencia su conformación por medio de la fórmula A es B. Expresado en otros términos, el poder del cantante japonés Psy reside en su destacada presencia en una de las entradas de la Enciclopedia Británica. De allí se sigue que la expresión metafórica el papá de los belados que encabeza los titulares de prensa de nuestro corpus obedece a las mismas motivaciones. Ver los casos (3), (4), (5), (6), (7), (8) y (10) del citado corpus.

Cabe destacar, asimismo, que uno de los casos que conforman el corpus de esta investigación, a saber "Europa quiere ser el papá de los helados de las redes 5G" presenta la particularidad de acompañar la expresión metafórica con un sustantivo de género femenino, como, a todas luces, resulta 'Europa'. La respuesta para este escollo puede ser rastreada, en primer lugar, en los presupuestos teóricos de Lakoff (2004), cuando mantiene que las naciones son comúnmente conceptualizadas como personas, y que en el campo de las relaciones internacionales y el desarrollo industrial prima la conceptualización de los países como niños. Un ejemplo clásico es el de la nación que es violada por una nación enemiga. Siguiendo esta idea, Lakoff apunta que la Guerra del Golfo Pérsico tuvo, en parte, su origen en la metaforización de Kuwait como la víctima indefensa que Estados Unidos debía rescatar del villano inherentemente irracional y demoniaco.

De similar tenor, es la investigación en la que Ramírez y Ramírez (2013) constatan que bajo los cuentos que conforman el volumen Margarita infanta, del escritor venezolano Francisco Suniaga, yace la conceptualización de la isla de Margarita como una niña a la que la modernidad y su industralización despojaron de su inocencia y belleza primigenia. Cada cuento se centra sobre aspectos que van desde el lenguaje, pasa por las leyendas de la región y van hasta inventos como el cine, y muestra con nostalgia el pasado glorioso de la isla.

A resultas de los argumentos expuestos, puede decirse que la conceptualización de un país como mujer o como hombre estriba en la representación del mismo en 
términos de debilidad o poder, respectivamente. Este hecho se pone de relieve cuando consideramos que, como Lakoff tiene a bien ilustrar, una nación puede ser violada o puede violar. En resumen, si una nación es conceptualizada como una mujer, es violada, es frágil, inocente, subdesarrollada; mientras que si es conceptualizada como hombre viola, es fuerte, experimentado, y desarrollado. El caso de Europa como el papá de los helados de las redes $5 \mathrm{G}$, por tanto, reposa en la noción de un continente industrial y poderoso en relación con el resto del mundo. De allí que asimile la expresión el papá de los helados en el terreno que le es propio.

\section{Conclusiones}

Se ha podido evidenciar que la expresión metafórica del habla cotidiana venezolana el papá de los helados descansa no en la arbitrariedad del lenguaje, sino, antes bien, en un entramado de motivaciones que incluyen: (a) la imagen esquemática de la metáfora orientacional EL PODER ES ARRIBA se proyecta sobre el esquema de un helado, en razón de la verticalidad y la parte alta y nuclear de este; (b) la experiencia corporal y el conocimiento cultural, como ocurre con el dulce y la crema; (c) la experiencia corporal que tienen los hablantes del español venezolano en relación con la autoridad paternal y su función determinante en la subjetividad del individuo durante su etapa infantil. Como se ha demostrado en minucia, este conjunto de elementos motivan a los hablantes del español de Venezuela a usar la imagen de un helado gigantesco en comparación con los sobrantes implícitos, a saber, el papá de todos los helados, para representar a un hombre que tiene poder sobre otros en un aspecto de la vida cotidiana.

El hecho de que un conjunto abundante de individuos coincidan en usar la misma expresión metafórica con un sentido pleno y sin reticencia se debe, en rigor, a que comparten tanto un ambiente físico como un bagaje cultural similar. En pocas palabras, en el sistema conceptual de todos estos individuos funciona la metáfora conceptual EL PODER ES ARRIBA, lo que le permite, entre otros usos, referirse a un estrato social de poder como 'alta sociedad'; estos individuos, bien sea por vía directa o por conocimiento enciclopédico, saben que un postre es un plato del cual pueden disponer habitualmente personas de cuantiosos ingresos económicos, ya que, por oposición, personas de escasos ingresos económicos se deben conformar con subsistir con los alimentos necesarios, si acaso pueden comer, cabe acotar; todos estos hablantes fueron niños y experimentaron la autoridad paterna.

Un evidente contraargumento que asoma en este punto es que existen hijos de madres divorciadas o, en el peor escenario, hijos que nunca se relacionaron con el padre. 
A este respecto, la prototipicidad nos da la solución, ya que los hablantes del español de Venezuela pensarían que el modelo prototípico de la categoría familia tiene como unos de sus rasgos fundamentales la autoridad paterna a la que nos hemos referido. Para puntualizarlo plenamente, digamos que un hablante del español de Venezuela, haya experimentado directamente la autoridad paterna o no, ha asimilado que en su cultura el padre es la autoridad del hogar.

Antes de dar por concluida esta investigación, conviene retomar el aspecto arbitrario que acordamos asumir a contrapelo de la idea postulada por Saussure (1945), según la cual la relación entre significante y significado del signo linguístico es arbitraria. A la luz de esto, habría sido legitimo hablar del primo de las chupetas, o el abuelo de la sardina, o acaso el bisnieto del arroz con coco, para referir a un hombre que tiene estatus de poder en algún aspecto cotidiano. El argumento a favor de esta relación sería, como se puede prever, que en algún momento hubo un acuerdo tácito por parte de los hablantes del español de Venezuela para usar 'el papá de los helados' con tal propósito. No obstante, nos hemos apoyado en un análisis contrastivo que ha hecho visible que, si bien en otros idiomas, 0 más atinado decir con otros significantes, expresiones metafóricas como 'el papá de los helados', 'la tapa del frasco', 'la crema de la crema', 'la crema y nata', 'the cream on the crop', 'the tall poppy' y la voz francófona 'créme de la créme' no son arbitrarias, sino que, en sustancia, se apoyan en la misma motivación experiencial y cultural de representar el poder como algo que está arriba, mientras que los subordinados se encuentran por debajo. Se dirá que esto se debe a que son expresiones metafóricas complejas, pero es un hecho que se puede obtener el mismo resultado de sustantivos metafóricos, como, digamos, 'rata', 'rat' (inglés) y 'ratten' (alemán), que motivadas por la experiencia cultural de ver ratas acabando con cosechas, ratas infecciosas y físicamente espantosas, se emplean para referirse a personas consideradas inmorales. De aquí se sigue que, por supuesto, las motivaciones coinciden porque la experiencia del mundo es similar. Huelga acotar que el mismo significado no puede ser contenido en otros significantes, no hay azar o acuerdo en usar indiferentemente una secuencia de sonidos.

Al término de esta investigación, se hace manifiesto el funcionamiento de nuestro sistema conceptual, para el cual el reciclaje de las experiencias previas y el conocimiento acumulado de los individuos constituye una operación que en etapas posteriores de la vida se convierten en elaboraciones más complejas del lenguaje y, por consiguiente, del pensamiento y del ser-hacer en el mundo. 


\section{Referencias bibliográficas}

Cuenca, M., \& Hilferty, J. (1999). Introducción a la lingüística cognitiva. Barcelona: Ariel.

D' Alessandro Bello, M. E. (2009). Diccionario del habla coloquial de Caracas. Caracas: Fundación para la Cultura Urbana.

Díaz, H. (2006). El poder es arriba. En M. di Stefano (comp.). Metáforas en uso. Buenos Aires: Editorial Biblos.

El Heraldo. (2014, febrero 18). Noel Sanvicente tiene apoyo del papá de los helados para dirigir La Vinotinto. [Página web en línea]. Recuperado de http://www.elheraldovenezuela.com/ noel-sanvicente-tiene-apoyo-del-papa-de-los-helados-para-dirigir-la-vinotinto/. [Consulta: 2015, mayo 1].

El polifacético “cantante” José Giovanni. (2014). "Gilberto Santa Rosa” es el papá de los belados en la salsa. [Documento en línea].Recuperado de http://josegiovanni1.blogspot. com/2014/06/un-sonerogran-bolerista-un-gran.html. [Consulta: 2015, septiembre 3] .

El Propio. (2012, octubre 13). Messi sigue siendo el papá de los belados para la prensa argentina. [Página web en línea]. Recuperado dehttp://host-173-246-50-7.biznesshosting. net/deportes/futbol/Messi-sigue-helados-prensa-Argentina_0_171584024.html. [Consulta: 2015: mayo 1].

El Propio. (2013, abril 11). Messi es el papá de los helados según Beckham. [Página web en línea]. Recuperado de http://www.elpropio.com/deportes/futbol/Messi-papa-heladosBeckham_0_279574509.html. [Consulta: 2015, mayo 1].

El Propio. (2013, enero 15). Vilanova cree que Pep es el papá de los helados. [Página web en línea]. Recuperado de http://www.elpropio.com/deportes/futbol/Vilanova-cree-Pep-papahelados_0_227979124.html. [Consulta: 2015, mayo 1].

El Propio. (2013, mayo 1). Psy es el papá de los helados en la Enciclopedia británica [Página web en línea]. Recuperado de http://www.elpropio.com/fama/espectaculos/Psy-papahelados-Enciclopedia-Britanica_0_291572679.html. [Consulta: 2015, mayo 1].

Estrada, L. (director). (2010). El infierno. [Película]. México: Bandidos films.

Guía.com.ve. (2013, mayo 7). Cabrera es el papá de los helados en la MLB. [Página web en línea]. Recuperado de http://www.guia.com.ve/noti/99547/cabrera-es-el-papa-de-los-helados-enla-mlb. [Consulta: 2015, mayo 1].

Hormiga Analítica (s/f). La industria de videojuegos en Venezuela está en pañales. [Página web en línea]. Recuperado de:http://www.hormigaanalitica.com/videojuegos/articulo/2505/Laindustria-de-videojuegos-en-Venezuela-esta-en-panales. [Consulta: 2015, septiembre 3]. 
Johnson, M. (1987). The body in the mind: the bodily basis of meaning, imagination, and reason. Chicago: The University of Chicago Press.

Johnson, M. (2007). The meaning of the body: aesthetics of human understanding. Chicago: The University of Chicago Press.

Kövecses, Z. (2010). Metaphor: a practical introduction. New York: Oxford University Press.

Lakoff, G. (1987). Women, fire, and dangerous things: what categories reveal about the mind. Chicago: The University of Chicago Press.

Lakoff, G. (2004). Don't think of an elephant!: know your values and frame the debate. Vermont: Chelsea Green Publishing.

Lakoff, G., \& Johnson, M. (2009). Metáforas de la vida cotidiana. Madrid: Cátedra.

LeaNoticias. (2014, febrero 12). Europa quiere ser el papá de los belados de las redes $5 G$. Recuperado de http://www.leanoticias.com/2014/02/12/europa-quiere-ser-el-papa-de-loshelados-de-las-redes-5g/. [Consulta: 2015, mayo 1].

Noticias Venezuela (2015, agosto 28). ¡El papá de los helados! Luís Arquímedes sigue arrasando. [Página web en línea]. Recuperado de http://noticiasvenezuela.org/2015/08/el-papa-delos-helados-luis-arquimedes-sigue-arrasando/. [Consulta: 2015, septiembre 3] .

Oloixarac, P. (2008). Las teorías salvajes. Barcelona: Alpha Decay.

Onfray, M. (2015). Appetites for thought: Philosophers and food. London: Reaktion Books.

Oxford Dicitonaries. (2015). [Página web en línea]. Recuperado de http://www.oxforddictionaries. com/es/definicion/espanol/mero. [Consulta: 2015, septiembre 3].

Pérez, F. J. (2002). Diccionario venezolano para jóvenes. Caracas: El Nacional.

Ramírez, A., \& Ramírez, M. (2013, Julio). Las metáforas de desastres naturales en la política venezolana. Ponencia presentada en el XXXEncuentro Nacional de Docentes e Investigadores de la Lingüística, Miranda.

Ramírez, M., \& Ramírez, A. (2013). Margarita Infanta: la niñez como representación de la época colonial de la Isla de Margarita. Revista Kaleidoscopio, 19, 86-93.

Ramírez, M., \& Ramírez, A. (2013). La metaforización orientacional de la bomosexualidad masculina en el filme contrarriente, de Javier Fuentes- León. Revista Conhisremi. Recuperado: conhisremi.iuttol.edu.ve/pdf/arti000178.pdf 
Real Academia Española. (2015) Diccionario de la lengua española (Vigésima segunda edición). [Diccionario en línea] Disponible en: http://www.rae.es/rae.html [Consulta: 2015, Enero 19].

Saussure, F. (1945). Curso de lingüística General. Buenos Aires: Editorial Losada. 